\title{
Detection of Cytolethal Distending Toxin and Other Virulence Characteristics of Enteropathogenic Escherichia coli Isolates from Diarrheal Patients in Republic of Korea
}

\author{
Kim, Jong-Hyun ${ }^{1}$, Jong-Chul Kim ${ }^{1}$, Yun-Ae Choo ${ }^{1}$, Hyun-Chul Jang ${ }^{1}$, Yeon-Hwa Choi ${ }^{1}$, Jae-Keun Chung ${ }^{2}$, \\ Seung-Hak Cho ${ }^{1}$, Mi-Seon Park ${ }^{1}$, and Bok-Kwon Lee ${ }^{1 *}$ \\ ${ }^{1}$ Division of Enteric Bacterial Infections, Center for Infectious Diseases, National Institute of Health, Seoul 122-701, Korea \\ ${ }^{2}$ Gwang-Ju Institute of Health and Environment, 502-240, Korea
}

Received: January 14, 2008 / Revised: August 21, 2008 / Accepted: September 4, 2008

Cytolethal distending toxins (CDTs) represent an emerging family of newly described bacterial products that are produced by a number of pathogens. The genes encoding these toxins have been identified as a cluster of three adjacent genes, $c d t A, c d t B$, and $c d t C$, plus 5 cdt genetic variants, designated as $c d t$-I, $c d t-\mathrm{II}, c d t-\mathrm{III}, c d t-\mathrm{IV}$, and $c d t$ $V$, have been identified to date. In this study, a general multiplex PCR system designed to detect Escherichia coli cdts was applied to investigate the presence of $\boldsymbol{c d t}$ genes among isolates. As a result, among $366 \mathrm{E}$. coli strains, $\mathbf{2 . 7 \%}$ were found to carry the $c d t B$ gene. In addition, the use of type-specific primers revealed the presence of $c d t$-I, $c d t \mathrm{IV}$, and $c d t-\mathrm{V}$ types of the $c d t$ gene, yet no $c d t$-II or $c d t$ III strains. The presence of other virulence genes (stxl, $s t x 2, e a e, b f p, e s p A, \operatorname{esp} B$, and $\operatorname{esp} D)$ was also investigated using a PCR assay. Among the $10 \mathrm{cdt} B$ gene-positive strains, 8 were identified as CDT-producing typical enteropathogenic $E$. coli (EPEC) strains $\left(e a e^{+}, b f p^{+}\right)$, whereas 2 were identified as CDT-producing atypical EPEC strains $\left(e a e^{+}, b f p^{-}\right)$. When comparing the cytotoxic activity of the CDT-producing typical and atypical EPEC strains, the CDT-producing atypical EPEC strains appeared to be less toxic than the CDT-producing typical EPEC strains.

Keywords: Cytolethal distending toxin, atypical EPEC, typical EPEC, bundle-forming pilus

Strains of enteropathogenic E. coli (EPEC) are an important cause of infantile diarrhea in developing countries [20]. EPEC can also be identified by their ability to cause the effacement of microvilli and intimate adherence between the bacterium and epithelial cells (A/E lesion) by polymerized

*Corresponding author

Phone: +82-2-380-2981; Fax: +82-2-352-4767;

E-mail: bokrates@nih.go.kr actin accumulation and the formation of pedestal-like structures beneath the adherent bacteria $[9,10]$. The locus of the enterocyte effacement (LEE) pathogenicity island contains type III secreted effector molecules $(\operatorname{esp} A, \operatorname{esp} B$, and $\operatorname{esp} D$ ) and an eae gene that encodes intimin, which in turn allows bacterial attachment to the gut mucosa. Other properties of EPEC include localized adherence (LA; bacteria form characteristic microcolonies on the surface of cells) mediated by the EPEC adherence factor (EAF) plasmid-encoded bundle-forming pili $(b f p)$ gene $[3,11]$. However, the EAF plasmid has not been detected among many EPEC isolates. EPEC strains can be further classified as typical or atypical and do not carry stx (Shiga toxin) genes. Typical and atypical EPEC both carry the LEE region and are distinguished by their phenotypic and genotypic characteristics, virulence properties, and reservoirs. Whereas typical EPEC carry the virulence plasmid EAF and are a leading cause of infantile diarrhea in developing countries, atypical EPEC do not harbor the EAF plasmid and seem to be an important cause of diarrhea in industrialized countries. Furthermore, typical EPEC have rarely been isolated from animals, as humans are the major natural reservoir for these pathogens [31], whereas atypical EPEC strains have been isolated from both animals and humans [1].

Cytolethal distending toxins (CDTs), first detected in 1987 in Escherichia coli O128 isolated from the stool of a child who was less than 2 years old and suffering from gastroenteritis [16], are an emerging family of toxins and produced by several pathogenic bacteria, such as Shigella dysenteriae [24], Campylobacter spp. [16], Haemophilus ducreyi [7], and Actinobacillus actinomycetemcomitans [17]. The CDTs in the abovementioned species are characterized with a unique structure of three overlapping genes highly homogeneous in all bacteria, yet in widely varying degrees [23, 27-29]. CDTs can be characterized based on their capacity to inhibit cellular proliferation by 
including an irreversible cell cycle block at the G2/M transition [26]. In addition, the CDTs produced by bacteria are composed of three polypeptides, $c d t A, c d t B$, and $c d t C$, which have molecular masses of approximately 30, 32, and $20 \mathrm{kDa}$, respectively. Numerous studies have already revealed the mode of CDT activity $[8,18,22]$, where the translocation of the CDT-B catalytic subunit into the host cell rests on the CDT-A and CDT-C subunits. Once in the cytoplasm, CDT-B can reach the nucleus and inflict DNA damage. CDT-B is structurally similar to DNaseI, and its activity depends on the presence of a phosphodiesterase consensus sequence. Accordingly, the aim of this study was to compare typical and atypical CDT-producing strains of EPEC isolated from diarrheal patients to evaluate their pathogenic potential and probable role as a cause of human disease.

\section{Materials And Methods}

\section{Bacterial Strains}

A total of $366 \mathrm{E}$. coli strains were isolated from diarrheal patients in 2005 , and the presence of the eae gene was investigated in all the strains using a PCR.

\section{PCR Analysis}

DNA from $100-\mu l$ aliquots of overnight cultures was extracted using a MegaExtract genomic kit (Toyobo, Japan) according to the manufacturer's instructions. The primers and PCR conditions are summarized in Table 1. The PCR ( 30 cycles) was performed in a total volume of $20 \mu \mathrm{l}$ containing $25 \mathrm{pM}$ concentrations of each primer, $200 \mu \mathrm{M}$ concentrations of each dNTP, $1.5 \mathrm{mM} \mathrm{MgCl}_{2}, 1 \mathrm{U}$ Taq polymerase (TaKaRa), $2 \mu$ l of a $10 \times$ polymerase buffer, and $1 \mu \mathrm{l}$ of the DNA preparation. The PCR products were visualized by ethidium bromide staining after electrophoresis on agarose gels $(1.8 \%)$. The amplicon produced using this method was $466 \mathrm{bp}$. To detect the $c d t$-I, II, III, and IV ( $c d t \mathrm{~B})$ genes, the PCR conditions were as previously described by Toth et al. [30] using the primers shown in Table 1. The PCR conditions described by Bielaszewska et al. [4] were used to amplify the $c d t-\mathrm{V}(c d t B)$ gene. Additional PCR tests using the primer sequences and PCR conditions described in Table 1 were conducted to determine the presence of the stxl, stx 2 , eae, bfp, espA, espB, and espD genes.

\section{Serotyping}

The determination of $\mathrm{O}$ antigens was carried out using the method described by Guinee et al. [12] employing all available O (O1$\mathrm{O} 185$ ) antisera. The $\mathrm{O}$ antisera were produced by LREC (Lugo, Spain).

Table 1. Primers used in this study.

\begin{tabular}{|c|c|c|c|c|c|}
\hline Gene & Orientation & Primer sequence $\left(5^{\prime}-3^{\prime}\right)$ & Product size $(\mathrm{bp})$ & Condition & Reference \\
\hline \multirow{2}{*}{$\operatorname{espA}$} & $\mathrm{F}$ & 5'-GTT TTT CAG GCT GCG ATT CT & \multirow{2}{*}{187} & & \multirow{2}{*}{ This study } \\
\hline & $\mathrm{R}$ & 5'-AGT TTG GCT TTC GCA TTC TT & & & \\
\hline \multirow{2}{*}{$\operatorname{esp} \mathrm{B}$} & $\mathrm{F}$ & 5'-GCC GTT TTT GAG AGC CAG AA & \multirow[b]{2}{*}{106} & & \multirow[b]{2}{*}{ This study } \\
\hline & $\mathrm{R}$ & 5'-AAA GAA CCT AAG ATC CCC A & & $94^{\circ} \mathrm{C}, 25 \mathrm{sec}$ & \\
\hline \multirow{2}{*}{$\operatorname{esp} \mathrm{D}$} & $\mathrm{F}$ & 5'-AAA AAG CAG CTC GAA GAA CA & \multirow{2}{*}{145} & $\begin{array}{l}55 \mathrm{C}, 25 \mathrm{sec} \\
77^{\circ} \mathrm{C} 25 \mathrm{sec}\end{array}$ & \multirow{2}{*}{ This study } \\
\hline & $\mathrm{R}$ & 5'-CCA ATG GCA ACA ACA GCC CA & & & \\
\hline \multirow{2}{*}{ eae } & $\mathrm{F}$ & 5'-ATG CTG GCA TTT GGT CAG GTC GG & \multirow{2}{*}{233} & & \multirow{2}{*}{ This study } \\
\hline & $\mathrm{R}$ & 5'-TGA CTC ATG CCA GCC GCT CAT GCG & & & \\
\hline \multirow{2}{*}{$b f p$} & $\mathrm{~F}$ & 5'-AAT GGT GCT TGC GCT TGC TGC & \multirow{2}{*}{320} & $94^{\circ} \mathrm{C}, 25 \mathrm{sec}$ & \multirow{2}{*}[13]{} \\
\hline & $\mathrm{R}$ & 5'-GCC GCT TTA TCC AAC CTG GTA & & $72^{\circ} \mathrm{C}, 25 \mathrm{sec}$ & \\
\hline \multirow{4}{*}{$c d t \mathrm{~B}$} & F1 & 5'-GAA AGT AAA TGG AAT ATA AAT GTC CG & \multirow{4}{*}{466} & & \\
\hline & $\mathrm{R} 1$ & 5'-AAA TCA CCA AGA ATC ATC CAG TTA & & $\begin{array}{l}94^{\circ} \mathrm{C}, 1 \mathrm{~min} \\
55^{\circ} \mathrm{C} 1 \mathrm{~min}\end{array}$ & \\
\hline & $\mathrm{F} 2$ & 5'-GAA AAT AAA TGG AAC ACA CAT GTC CG & & $72^{\circ} \mathrm{C} 1 \mathrm{~min}$ & \\
\hline & R2 & 5'-AAA TCT CCT GCA ATC ATC CAG TTA & & & \\
\hline \multirow{2}{*}{$c d t$ type I } & $\mathrm{F}$ & 5'-CAA TAG TCG CCC ACA GGA & \multirow{2}{*}{411} & & \\
\hline & $\mathrm{R}$ & 5'-ATA ATC AAG AAC ACC ACC AC & & & {$[30]$} \\
\hline \multirow{2}{*}{$c d t$ type II } & $\mathrm{F}$ & 5'-GAA AGT AAA TGG AAT ATA AAT GTC CG & \multirow{2}{*}{556} & & {$[30]$} \\
\hline & $\mathrm{R}$ & 5'-TTT GTG TTG CCG CCG CTG GTG AAA & & $94^{\circ} \mathrm{C}, 1 \mathrm{~min}$ & \\
\hline \multirow{2}{*}{$c d t$ type III } & $\mathrm{F}$ & 5'-GAA AGT AAA TGG AAT ATA AAT GTC CG & \multirow{2}{*}{555} & $54^{\circ} \mathrm{C}, 1 \mathrm{~min}$ & \\
\hline & $\mathrm{R}$ & 5'-TTT GTG TCG GTG CAG CAG GGA AAA & & $72^{\circ} \mathrm{C}, 1 \mathrm{~min}$ & \\
\hline \multirow{2}{*}{$c d t$ type IV } & $\mathrm{F}$ & 5'-CCT GAT GGT TCA GGA GGC TGG TTC & \multirow{2}{*}{350} & & \\
\hline & $\mathrm{R}$ & 5'-TTG CTC CAG AAT CTA TAC CT & & & \\
\hline \multirow{2}{*}{$c d t$ type $\mathrm{V}$} & $\mathrm{F}$ & 5'-AGC ACC CGC AGT ATC TTT GA & \multirow{2}{*}{1363} & & \multirow{2}{*}{ [15] } \\
\hline & $\mathrm{R}$ & 5'-AGC CTC TTT TAT CGT CTG GA & & & \\
\hline \multirow{2}{*}{ cnf 1} & $\mathrm{~F}$ & 5'-GGC GAC AAA TGC AGT ATT GCT TGG & \multirow{2}{*}{533} & & \multirow{4}{*}[5]{} \\
\hline & $\mathrm{R}$ & 5'-GAC GTT GGT TGC GGT AAT TTT GGG & & $94^{\circ} \mathrm{C}, 1 \mathrm{~min}$ & \\
\hline \multirow{2}{*}{$\operatorname{cnf} 2$} & $\mathrm{~F}$ & 5'-GTG AGG CTC AAC GAG ATT ATG CAC TG & & $62^{\circ} \mathrm{C}, 1 \mathrm{~min}$ & \\
\hline & $\mathrm{R}$ & 5'-CCA CGC TTC TTC TTC AGT TGT TCC TC & 552 & $12 \mathrm{C}, 1 \mathrm{~min}$ & \\
\hline
\end{tabular}


Table 2. Serotype, $c d t$ types, and virulence gene profiles of $E$. coli strains possessing $c d t B$.

\begin{tabular}{|c|c|c|c|c|c|c|c|c|c|c|c|}
\hline \multirow{2}{*}{ Strain } & \multirow[t]{2}{*}{ Serotype } & \multicolumn{8}{|c|}{ PCR result of virulence genes ${ }^{c}$} & \multirow{2}{*}{$c d t$ type } & \multirow{2}{*}{$\begin{array}{l}\text { Reciprocal titer of } c d t \\
\text { in CHO cell assay }\end{array}$} \\
\hline & & eae & $b f p$ & espA & espB & espD & stx 1 & stx 2 & $c d t B$ & & \\
\hline $05-137$ & O167 & + & + & + & + & + & - & - & + & IV & 128 \\
\hline $05-204$ & O6 & + & + & - & - & - & - & - & + & IV & 128 \\
\hline $05-654$ & $\mathrm{OUT}^{\mathrm{a}}$ & + & + & + & + & + & - & - & + & I & 32 \\
\hline $05-1070$ & OUT $^{\mathrm{a}}$ & + & + & + & + & + & - & - & + & $\mathrm{I}$ & 128 \\
\hline $05-1072$ & OUT $^{\mathrm{a}}$ & + & - & - & - & - & - & - & + & I & 8 \\
\hline 05-1394 & $\mathrm{OUT}^{\mathrm{a}}$ & + & + & - & + & + & - & - & + & IV & 128 \\
\hline $05-1569$ & $\mathrm{O} 179$ & + & + & - & + & + & - & - & + & IV & 64 \\
\hline $05-1633$ & O142 & + & + & - & + & + & - & - & + & I & 64 \\
\hline $05-1745$ & O88 & + & + & + & + & + & - & - & + & V & $\mathrm{ND}^{\mathrm{b}}$ \\
\hline $05-2119$ & $\mathrm{O} 21$ & + & - & - & - & - & - & - & + & I & 16 \\
\hline
\end{tabular}

${ }^{\mathrm{a} O U T}$, not typeable.

${ }^{\mathrm{b}} \mathrm{ND}$, Not determined.

${ }^{c}$ Virulence genes: eae, intimin; $b f p$, bundle-forming pilus; esp $A$, EPEC-secreted protein A; espB, EPEC-secreted protein B; espD, EPEC-secreted protein D; stx 1 , Shiga toxin $1 ;$ stx 2 , Shiga toxin $2 ; c d t B$, cytolethal distending toxin B.

\section{CHO Cell Assay}

The CDT assays were conducted using Chinese hamster ovary (CHO) cells. Briefly, supernatants taken from cultures of $E$. coli grown overnight at $37^{\circ} \mathrm{C}$ in a DMEM with $5 \%$ fetal calf serum were filter-sterilized, and then $1 \mathrm{ml}$ of the supernatants or 2-fold dilutions were added in duplicate to $10^{3}$ freshly seeded CHO cells in $1.5 \mathrm{ml}$ of the DMEM in 6-well tissue culture plates (Falcon 3502). The assay mixtures were incubated for 5 days at $37^{\circ} \mathrm{C}$ under $5 \% \mathrm{CO}_{2}$, and examined daily for typical distending effects [15]. The CDT titer was defined as the highest filtrate dilution that caused distension in $50 \%$ of the $\mathrm{CHO}$ cells.

\section{Results}

\section{PCR Analysis}

The 366 strains isolated from diarrheal patients were initially screened using primers designed for the detection of EPEC $c d t B$. The results indicated that $10(2.7 \%)$ strains yielded an amplicon with the predicted size (466 bp). Nine of these strains were found to be CDT production-positive when a conventional cytotoxic assay was used (Table 2). Additional analyses were then conducted using primers derived from the $c d t B$ region, which is very highly conserved in all $c d t B \mathrm{~s}$, to detect $c d t$ sequences in several different genera (Table 1). Four primers designed to detect the presence of the $b f p, \operatorname{esp} A, \operatorname{esp} B$, and $\operatorname{esp} D$ genes were used in the PCR assay. In the PCR, amplicons with the expected sizes of $326 \mathrm{bp}, 187 \mathrm{bp}, 106 \mathrm{bp}$, and $145 \mathrm{bp}$ were generated from $8(b f p), 4(\operatorname{esp} A), 7(\operatorname{esp} B)$, and $7(\operatorname{esp} D)$ of the tested isolates, respectively. In addition, 8 of the EPEC strains were found to contain the $b f p$ gene encoding a bundle, which is the structural subunit of the bundle-forming pilus expressed by typical EPEC $\left(e a e^{+}\right.$and $\left.b f p^{+}\right)$strains. However, two of the EPEC strains did not possess the bfp gene expressed by atypical EPEC ( $e a e^{+}$and $\left.b f p^{-}\right)$strains (Table 2$)$.

\section{Typing of $\boldsymbol{c d t}$ Genes and Serotype}

The CDT-producing EPEC strains were tested for their $c d t$ types (Fig. 1). However, $c d t$-II and $c d t$-III were not identified in any of these strains (Table 2). As such, the CDT-producing E. coli isolates belonged to serotypes O21, O142, and not typeable (cdt-I-positive strains), serotypes O6, O167, O179, and not typeable (cdt-IV-positive strains), and serotype O88 (cdt-V-positive strain).

\section{CHO Cell Assay}

The CDT activity was evaluated by microscopic observation of Chinese hamster ovary cells 5 days after exposure to the CDT-producing E. coli cultured supernatants. Whereas the supernatant from $E$. coli DH5 $\alpha$ did not alter the morphology of the Chinese hamster ovary cells, the Chinese hamster
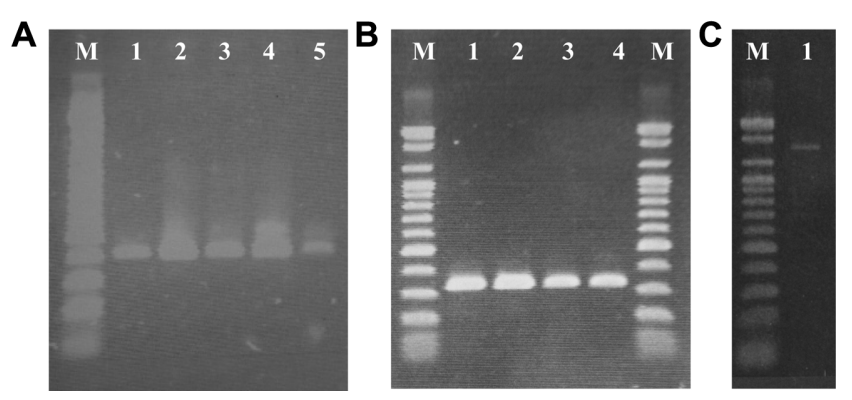

Fig. 1. PCR products produced by $c d t-\mathrm{I}, c d t-\mathrm{IV}$, and $c d t-\mathrm{V}$ CDT-producing EPEC strains.

A. PCR products $(411 \mathrm{bp})$ amplified from indicated EPEC using $c d t$-Ispecific primers described by Toth et al. [29]. Lanes: 1, 05-654; 2, 051070; 3, 05-1072; 4, 05-1633; 5, 05-2119; M, Molecular weight marker (100-bp ladder). B. PCR products ( $350 \mathrm{bp}$ ) amplified from indicated EPEC using $c d t$-IV-specific primers described by Toth et al. [29]. Lanes: 1, 05$137 ; 2,05-204 ; 3,05-1394 ; 4,05-1569$. C. PCR products $(1,363 \mathrm{bp})$ amplified from indicated EPEC using $c d t$-V-specific primers described by Bielaszewska et al. [4]. Lane: 1, 05-1745. 


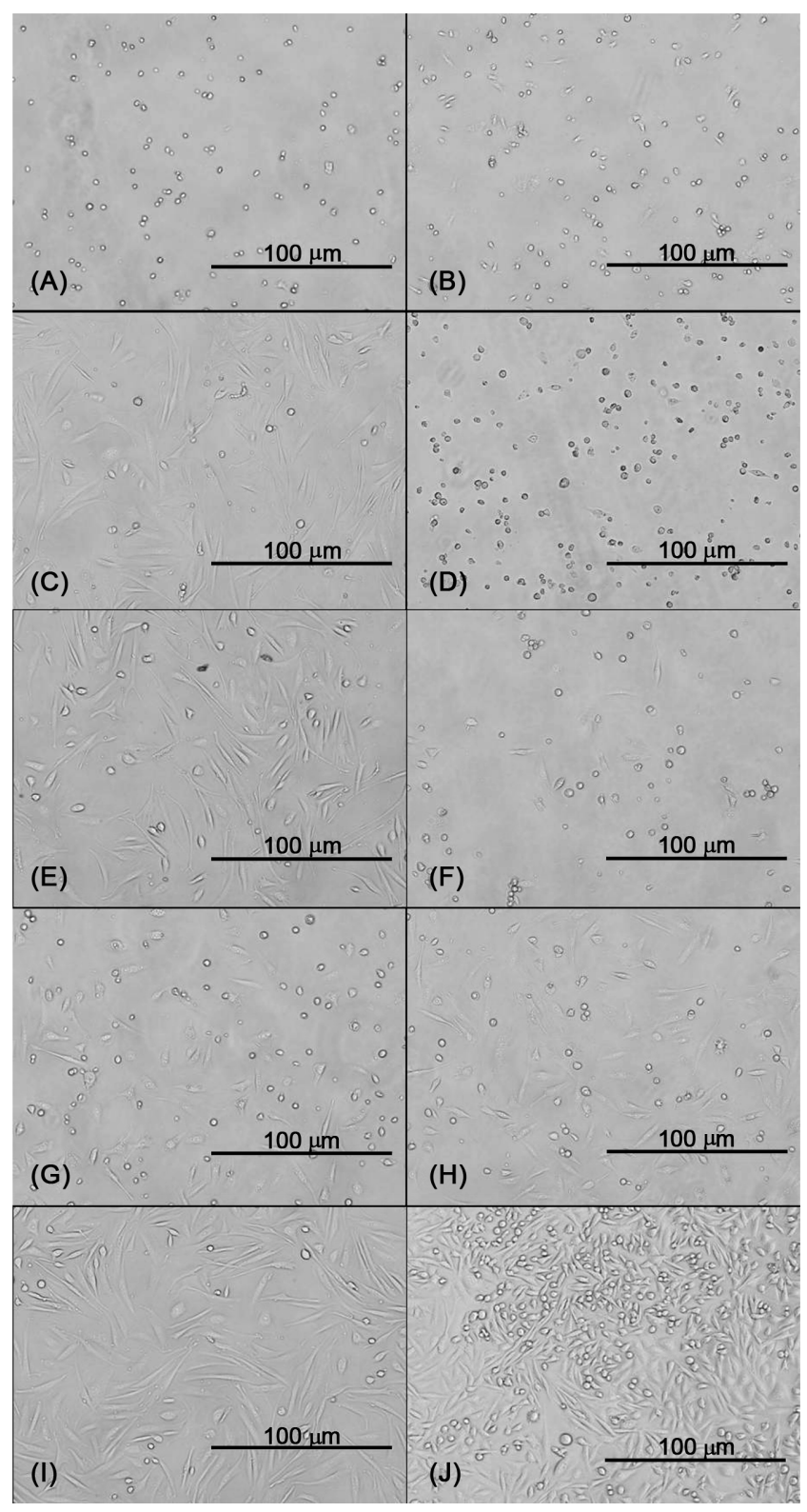

Fig. 2. Appearance of Chinese hamster ovary cells after 5 days of exposure to culture supernatant of CDT-producing EPEC strains.

(A) CDT-producing typical EPEC (05-137) culture supernatant at 1/8 dilution; (B) Typical EPEC (05-204); (C) Typical EPEC (05-654); (D) Typical EPEC (05-1070); (E) Atypical EPEC (05-1072); (F) Typical EPEC (05-1394); (G) Typical EPEC (05-1569); (H) Typical EPEC (05-1633); (I) Atypical EPEC (05-2119); (J) Negative control.

ovary cells treated with supernatants from cultures of the CDT-producing $E$. coli strains exhibited the characteristic alterations in shape caused by CDT (Fig. 2). Moreover, the distending effects of increasing the concentration titers of the total cell supernatants from the various CDT-producing $E$. coli isolates on the Chinese hamster ovary cells are shown in Table 2.

\section{DISCUSSION}

Since CDT was first identified in E. coli by Johnson and Lior in 1987 [16], several studies have reported that $c d t$ can be produced by intestinal and extraintestinal pathogenic bacteria $[17,21,24]$. In addition, other studies have revealed differences in the sequences of $E$. coli $c d t$, allowing it to be divided into different types [18, 25, 27, 30]. Nonetheless, when the $c d t$ operons obtained from Campylobacter coli and $C$. jejuni were sequenced, they were shown to be much more homologous than the E. coli cdt genes [28]. Furthermore, Albert et al. [2] found no significant association between CDT-positive E. coli strains and diarrhea; however, the toxin was recently shown to have diarrheagenic properties in an animal model [23].

This study was conducted to detect and identify different $c d t$ genes among EPEC strains isolated from diarrheal patients in Korea. A general PCR system [30] designed to detect $E$. coli $c d t$ s was employed to investigate the presence of $c d t$ genes among the isolates, and among $366 \mathrm{E}$. coli strains, $2.7 \%$ were found to carry the $c d t B$ gene. CDT production has been associated with EPEC serogroups [5]. For example, the frequency of the $c d t$ gene in EPEC strains has been reported as 2.8\% and 6.4\% in studies conducted in Brazil [14] and India [6], respectively, similar to the frequency observed in this study. Using type-specific primers, it was demonstrated that $c d t$-I, $c d t$ $\mathrm{IV}$, and $c d t-\mathrm{V}$ types of the $c d t$ gene were present in the isolates evaluated in this study, although the present collection did not contain any $c d t$-II and $c d t$-III strains. The distribution of virulence genes is presented in Table 2 . All the CDT-producing EPEC strains were positive for eae (intimin). Eight out of 10 strains were $b f p$ (EAF plasmidencoded bundle-forming pili)-positive. CDT production is associated with EPEC [2, 6], and it has also been reported to be associated with the eae gene $[4,14,18]$. When comparing the cytotoxic activity of culture supernatants of the CDT-producing atypical EPEC $\left(e a e^{+}, b f p^{-}\right)$and typical EPEC $\left(e a e^{+}, b f p^{+}\right)$strains, the CDT-producing atypical EPEC strains appeared to be less toxic than the CDT-producing typical EPEC strains. Although the underlying mechanisms to explain the associations observed in the present study are not known, the results imply that bundleforming pili ( $b f p$ ) were related to the CDT distending effect.

In conclusion, this study would appear to be the first to report the possible association of CDT-producing EPEC with diarrheal patients in the Republic of Korea. Thus, the present results would seem to suggest that CDT-producing $E$. coli represent a new category of diarrheagenic E. coli attributed to diarrhea. Further studies are required to investigate a correlation among CDT-producing E. coli, virulence genes, and crucial diarrhea. 


\section{REFERENCES}

1. Aktan, I., K. A. Sprigings, R. M. La Ragione, L. M. Faulkner, G. A. Paiba, and M. J. Woodward. 2004. Characterization of attaching-effacing Escherichia coli isolated from animals at slaughter in England and Wales. Vet. Microbiol. 102: 43-53.

2. Albert, M. J., S. M. Faruque, A. S. Faruque, K. A. Bettelheim, P. K. Neogi, N. A. Bhuiyan, and J. B. Kaper. 1996. Controlled study of cytolethal distending toxin-producing Escherichia coli infections in Bangladeshi children. J. Clin. Microbiol. 34: 717-719.

3. Baldini, M. M., J. B. Kaper, M. M. Levine, D. C. Candy, and H. W. Moon. 1983. Plasmid-mediated adhesion in enteropathogenic Escherichia coli. J. Pediatr. Gastroenterol. Nutr. 2: 534-538.

4. Bielaszewska, M., M. Fell, L. Greune, R. Prager, A. Fruth, H. Tschape, M. A. Schmidt, and H. Karch. 2004. Characterization of cytolethal distending toxin genes and expression in Shiga toxin-producing Escherichia coli strains of non-O157 serogroups. Infect. Immun. 72: 1812-1816.

5. Blanco, J., M. Blanco, J. Blanco, M. P. Alonso, C. Balsalobre, M. Mourino, C. Madrid, and A. Juarez. 1996. Polymerase chain reaction for detection of Escherichia coli strains producing cytotoxic necrotizing factor type 1 and type 2 (CNF1 and CNF2). J. Microbiol. Methods 26: 95-101.

6. Bouzari, S. and A. Varghese. 1990. Cytolethal distending toxin (CLDT) production by enteropathogenic Escherichia coli (EPEC). FEMS Microbiol. Lett. 59: 193-198.

7. Cope, L. D., S. Lumbley, J. L. Latimer, J. Klesney-Tait, M. K. Stevens, L. S. Johnson, et al. 1997. A diffusible cytotoxin of Haemophilus ducreyi. Proc. Natl. Acad. Sci. U.S.A. 94: 4056-4061.

8. De Rycke, J. and E. Oswald. 2001. Cytolethal distending toxin (CDT): A bacterial weapon to control host cell proliferation? FEMS Microbiol. Lett. 2003: 141-148.

9. DeVinney, R., A. Gauthier, A. Abe, and B. B. Finlay. 1999. Enteropathogenic Escherichia coli: A pathogen that inserts its own receptor into host cells. Cell. Mol. Life Sci. 55: 961-976.

10. Frankel, G., A. D. Phillips, I. Rosenshine, G. Dougan, J. B. Kaper, and S. Knutton. 1998. Enteropathogenic and enterohaemorrhagic Escherichia coli: More subversive elements. Mol. Microbiol. 30: 911-921.

11. Giron, J. A., A. S. Ho, and G. K. Schoolnik. 1991. An inducible bundle-forming pilus of enteropathogenic Escherichia coli. Science 254: 710-713.

12. Guinee, P. A. M., W. H. Jansen, T. Wadstrom, and R. Sellwood. 1981. Escherichia coli associated with neonatal diarrhea in piglets and calves, pp. 126-162. In P. W. Leeww and P. A. M. Guinee (eds.), Laboratory Diagnosis in Neonatal Calf and Pig Diarrhea: Current Topics in Veterinary and Animal Science. Martinus-Nijhoff, The Hague, Netherlands.

13. Gunzbug, S. T., N. G. Tornieporth, and L. W. Riley. 1995. Identification of enterophatogenic Escherichia coli by PCRbased detection of the bundle-forming pilus gene. J. Clin. Microbiol. 33: 1375-1377.

14. Guth, B. E., R. Giraldi, T. A. Gomes, and L. R. Marques. 1994. Survey of cytotoxin production among Escherichia coli strains characterized as enteropathogenic (EPEC) by serotyping and presence of EPEC adherence factor (EAF) sequences. Can. J. Microbiol. 40: 341-344.

15. Janka, A., M. Bielaszewska, U. Dobrindt, L. Greune, M. A. Schmidt, and H. Karch. 2003. Cytolethal distending toxin gene cluster in enterohemorrhagic Escherichia coli $0157: \mathrm{H}-$ and O157:H7: Characterization and evolutionary considerations. Infect. Immun. 71: 3634-3638.

16. Johnson, W. M. and H. Lior. 1987. Response of Chinese hamster ovary cells to a cytolethal distending toxin (CDT) of Escherichia coli and possible misinterpretation as heat-labile (LT) enterotoxin. FEMS Microbiol. Lett. 43: 19-23.

17. Johnson, W. M. and H. Lior. 1988. A new heat-labile cytolethal distending toxin (CLDT) produced by Escherichia coli isolates from clinical material. Microb. Pathog. 4: 103-113.

18. La Ragione, R. M., I. M. McLaren, G. Foster, W. A. Cooley, and M. J. Woodward. 2002. Phenotypic and genotypic characterization of avian Escherichia coli O86:K61 isolates possessing a gamma-like intimin. Appl. Environ. Microbiol. 68: 4932-4942.

19. Lara-Tejero, M. and J. E. Galan. 2002. Cytolethal distending toxin: Limited damage as a strategy to modulate cellular functions. Trends Microbiol. 10: 147-152.

20. Levine, M. M. and R. Edelman. 1984. Enteropathogenic Escherichia coli of classic serotypes associated with infant diarrhea: Epidemiology and pathogenesis. Epidemiol. Rev. 6: 31-51.

21. Mainil, J. G., E. Jacquemin, and E. Oswald. 2003. Prevalence and identity of $c d t$-related sequences in necrotoxigenic Escherichia coli. Vet. Microbiol. 94: 159-165.

22. Ohara, M., E. Oswald, and M. Sugai. 2004. Cytolethal distending toxin: A bacterial bullet targeted to nucleus. $J$. Biochem (Tokyo) 126: 409-413.

23. Okuda, J., M. Fukumoto, Y. Takeda, and M. Nishibuchi. 1997. Examination of diarrheagenicity of cytolethal distending toxin: Suckling mouse response to the products of the $c d t A B C$ genes of Shigella dysenteriae. Infect. Immun. 65: 428-433.

24. Okuda, J., H. Kurazono, and Y. Takeda. 1995. Distribution of the cytolethal distending toxin A gene (cdtA) among species of Shigella and Vibrio, and cloning and sequencing of the $c d t$ gene from Shigella dysenteriae. Microb. Pathog. 18: 167-172.

25. Pass, M. A., R. Odedra, and R. M. Batt. 2000. Multiplex PCRs for identification of Escherichia coli virulence genes. J. Clin. Microbiol. 38: 2001-2004.

26. Peres, S. Y., O. Marches, F. Daigle, J. P. Nougayrede, F. Herault, C. Tasca, J. De Rycke, and E. Oswald. 1997. A new cytolethal distending toxin (CDT) from Escherichia coli producing CNF2 blocks HeLa cell division in G2/M phase. Mol. Microbiol. 24: 1095-1107.

27. Pickett, C. L., D. L. Cottle, E. C. Pesci, and G. Bikah. 1994. Cloning, sequencing, and expression of the Escherichia coli cytolethal distending toxin genes. Infect. Immun. 62: 1046-1051.

28. Pickett, C. L. and C. A. Whitehouse. 1999. The cytolethal distending toxin family. Trends Microbiol. 7: 292-297.

29. Scott, D. A. and J. B. Kaper. 1994. Cloning and sequencing of the genes encoding Escherichia coli cytolethal distending toxin. Infect. Immun. 62: 244-251.

30. Toth, I., F. Herault, L. Beutin, and E. Oswald. 2003. Production of cytolethal distending toxins by pathogenic Escherichia coli strains isolated from human and animal sources: Establishment of the existence of a new $c d t$ variant (type IV). J. Clin. Microbiol. 41: 4285-4291.

31. Trabulsi, L. R., R. Keller, and T. A. Tardelli Gomes. 2002. Typical and atypical enteropathogenic Escherichia coli. Emerg. Infect. Dis. 8: 508-513. 